\title{
Symmetry and Isometry of Human Adult Hyoid Bone: A Cadaveric Study
}

\author{
Dr. Savitha $\mathrm{V}^{1 *}$, Dr. Vidya $\mathrm{H} \mathrm{K}^{2}$
}

${ }^{1}$ Assistant Professor, Department of Anatomy, Adichunchanagiri Institute of Medical Sciences affiliated to Adichunchanagiri University, B.G Nagara Karnataka, India

${ }^{2}$ Associate Professor, Department of Anatomy, Shridevi Institute of Medical Sciences and Research Hospital, Tumkur. Karnataka, India

*Corresponding author: Dr. Savitha V

\section{Abstract}

Background: The hyoid bone is of considerable forensic interest because of its susceptibility to fracture during manual strangulation, hanging and other forms of neck compression. It is also frequently injured in road traffic accidents and may cause significant airway concerns. Whatever may be the reasons, why only some hyoid bones fracture and others do not may be related to the nature, magnitude, position of force applied to the neck, age of victim, nature of instrument (ligature or hand) used to strangle and anatomical features of the hyoid bone such as rigidity, shape of the bone and symmetry of greater horns. Aim: To know the incidence of symmetry and isometry of human hyoid bones in both sexes. Materials \& Methods: Present study includes 60 hyoid bones (male: female, 30:30) collected from the cadavers of known age and sex during autopsies (October 2013 to April 2016) at Mysore Medical College and Research Institute, Mysore. Numbering the bones was done with prefix M/F (M-male, F- female).Their outline was drawn on the graphpaper to study the symmetry and isometry of the bone. Results: $50 \%$ of the hyoid bones were symmetrical (M:F - 45\%:54\%) while remaining 50\% were asymmetrical (M:F - 54\%:45\%). Anisometric bones were more (58\%) as compared with isometric $(42 \%)$ bones in both the sexes. In males 17 bones were anisometric, 13 bones were isometric where as in females 18 bones were anisometric, and 12 bones were isometric. Conclusion: Hyoid bone is not bilaterally symmetrical bone.

Keywords: Hyoid bone, isometry, anisometry, symmetry, asymmetry.

Copyright @ 2020: This is an open-access article distributed under the terms of the Creative Commons Attribution license which permits unrestricted use, distribution, and reproduction in any medium for non-commercial use (NonCommercial, or CC-BY-NC) provided the original author and source are credited.

\section{INTRODUCTION}

The hyoid bone is a rather neglected structure of the human skeleton, which has not been given sufficient attention [1]. It is a part of viscerocranium placed between the tongue and thyroid cartilage to which it is connected by thyro-hyoid membrane. Its name is derived from the Greek word hyoeides meaning 'shaped like the letter Upsilon' "U" [2].

It is an integral component of the hyoid apparatus, because it provides attachment for the muscles of this apparatus which regulates mastication, deglutition and phonation. It consists of a central body and two paired processes the lesser and the greater cornua [3].

\section{MATERIAL AND METHODS}

Present study includes 60 specimens (male: female, 30:30) of hyoid bones collected from the cadavers during autopsies (2013 to 2016) at Mysore Medical College and research Institute, Mysore. All specimens were from individuals aged between 19 to 80 . The damaged hyoid bones in cases of hanging and strangulation were excluded from the study. The specimens were stored in $10 \%$ formaldehyde solution.

In these specimens laryngeal cartilages, thyroid gland, infrahyoid muscles and thyro hyoid membranes were dissected out and removed. Initially infrahyoid muscles and thyrohyoid membrane were cut beyond $1 \mathrm{~cm}$ of hyoid bone, then muscular and ligamentous structures were removed. During dissection care was taken to preserve the lesser cornua of hyoid bone and then each bone was completely dried in air for a week. Bones were labelled from 1 to 60 with suffix M (male) or F (female). Each hyoid bone was examined for Symmetry/ asymmetry and isometry/ anisometry as follows.

\section{Symmetry}

For determining the symmetry of the hyoid bone, the outline of the bone was drawn on graph paper by pencil. The distal ends of the two greater cornua 
were joined ( $\mathrm{AB}$ in Figure 1).Major transverse axis was also drawn (CD in Figure 1).A line was drawn in the mid-sagittal axis of the bone from the posterior surface of the body intersecting the previous lines at points $\mathrm{P}$ and $\mathrm{P}^{1}$. If the distance $\mathrm{CP}=\mathrm{PD}$, then the bone was labelled as symmetrical bone and if not, it was labelled as asymmetrical.

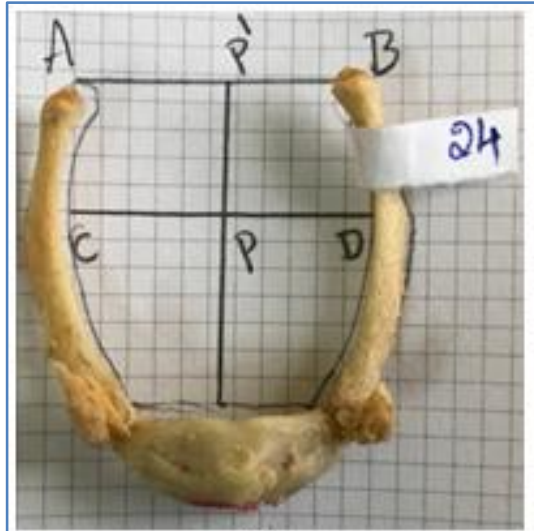

(a)

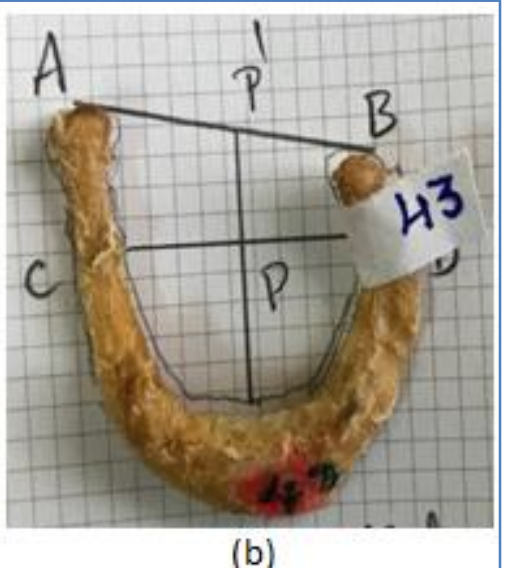

(b)

Fig-01: Symmetry of hyoid bones (a) symmetrical and isometric (b) symmetrical and anisometric

\section{Isometry}

A bone is isometric if the tips of both greater cornua fallin the same coronal plane. If it is not so, the hyoid boneis anisometric. For this, the bone was kept on graph paper. With body lying parallel to $\mathrm{x}$-axis and then a line was drawn touching the tips of the two greater cornua. If it is parallel to $\mathrm{x}$-axis it is isometric, otherwise anisometric.

Here, it is worth mentioning that the length of two greater cornua may not be necessarily same in isometric bones (Figure 2).

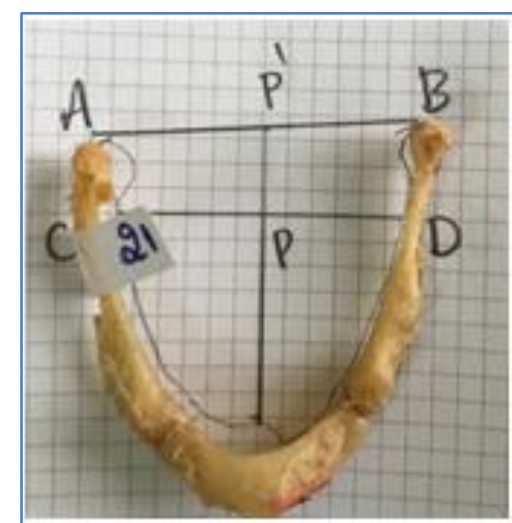

(a)

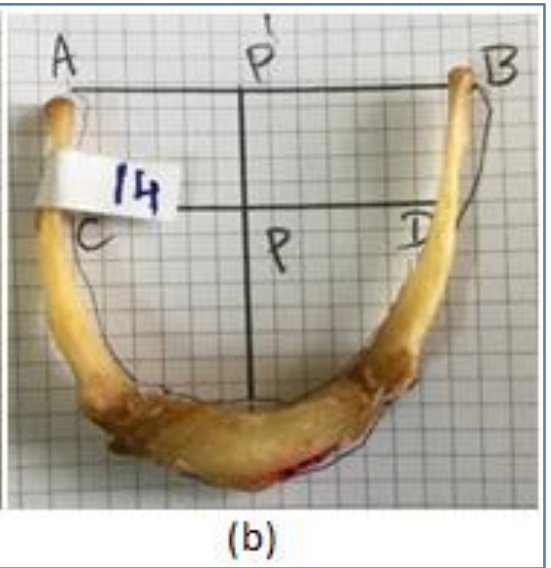

Fig-2: Symmetry and isometry of hyoid bones. (a) Symmetrical but anisometric (b) Isometric but asymmetrical

\section{RESULTS}

\section{Symmetry}

In the present study, out of 60 bones, $30(50 \%)$

bones were symmetrical and $30 \quad(50 \%)$ were asymmetrical [Table 1].

\section{Isometry}

In the present study, Out of 60 bones, 25 bones $(41.66 \%)$ (13 in males and 12 in females) were isometric. Rest of 35 bones (58.33\%) (17 in males and 18 in females) were anisometric [Table 1].

Table-01: Incidence of symmetry and isometry in the present study

\begin{tabular}{|l|l|l|l|l|l|l|l|l|}
\hline \multirow{2}{*}{ Sex } & \multicolumn{2}{|c|}{ isometric } & \multicolumn{2}{c|}{ anisometric } & \multicolumn{2}{c|}{ asymmetry } & \multicolumn{2}{c|}{ symmetry } \\
\cline { 2 - 9 } & No of bones & $\%$ & No of bones & $\%$ & No of bones & $\%$ & No of bones & $\%$ \\
\hline Male & 13 & 43.33 & 17 & 56.66 & 16 & 53.33 & 14 & 46.66 \\
\hline Female & 12 & 40 & 18 & 60 & 14 & 46.66 & 16 & 53.33 \\
\hline Total & 25 & 41.66 & 35 & 58.33 & 30 & 50 & 30 & 50 \\
\hline
\end{tabular}




\section{DISCUSSION}

Table 2 compares the incidence of symmetry and isometry of hyoid bone in male and females with the earlier studies. The present study shows that the incidence of symmetrical bones were more in females and asymmetrical bones were more in males, while in the study conducted by Bhavna kalyan [6] no such difference was observed, the incidence of symmetrical bones were $40 \%$ and asymmetrical bones were $60 \%$ in both male and females. Where as in other studies [2, 4, $5,7]$ the incidence of symmetrical bones were more in males and asymmetrical bones were more in females.

Table-02: Comparison of present study with other studies

\begin{tabular}{|c|c|c|c|c|c|c|c|c|c|c|}
\hline \multirow[t]{2}{*}{ Authors } & \multirow{2}{*}{$\begin{array}{l}\text { Sample } \\
\text { Size }\end{array}$} & \multirow[t]{2}{*}{ Total } & \multicolumn{2}{|c|}{ symmetric } & \multicolumn{2}{|c|}{ asymmetric } & \multicolumn{2}{|c|}{ isometry } & \multicolumn{2}{|c|}{ anisometry } \\
\hline & & & No & $\%$ & No & $\%$ & No & $\%$ & No & $\%$ \\
\hline Papadopoulos [2] & $\begin{array}{l}\text { M- } 38 \\
\text { F- } 38\end{array}$ & 76 & $\begin{array}{l}18 \\
22\end{array}$ & $\begin{array}{l}47.36 \\
57.89\end{array}$ & $\begin{array}{l}20 \\
16\end{array}$ & $\begin{array}{l}52.63 \\
42.10\end{array}$ & $\begin{array}{l}18 \\
20\end{array}$ & $\begin{array}{l}47.36 \\
52.63\end{array}$ & $\begin{array}{l}20 \\
18\end{array}$ & $\begin{array}{l}52.63 \\
47.36\end{array}$ \\
\hline Leksan et al.[4] & $\begin{array}{l}\text { M-35 } \\
\text { F-35 }\end{array}$ & 70 & $\begin{array}{l}33 \\
27 \\
\end{array}$ & $\begin{array}{l}94.28 \\
77.14 \\
\end{array}$ & $\begin{array}{l}2 \\
8 \\
\end{array}$ & $\begin{array}{l}5.71 \\
22.85 \\
\end{array}$ & & & & \\
\hline Jadhav Aswini S [5] & $\begin{array}{l}\text { M-51 } \\
\text { F-40 }\end{array}$ & 91 & $\begin{array}{l}32 \\
30\end{array}$ & $\begin{array}{l}62.74 \\
75\end{array}$ & $\begin{array}{l}19 \\
10\end{array}$ & $\begin{array}{l}37.25 \\
25\end{array}$ & $\begin{array}{l}36 \\
32\end{array}$ & $\begin{array}{l}70.58 \\
80\end{array}$ & $\begin{array}{l}15 \\
8\end{array}$ & $\begin{array}{l}29.41 \\
20\end{array}$ \\
\hline Bhavna kalyan [6] & $\begin{array}{l}\text { M-15 } \\
\text { F-15 }\end{array}$ & 30 & $\begin{array}{l}6 \\
6\end{array}$ & $\begin{array}{l}40 \\
40\end{array}$ & $\begin{array}{l}9 \\
9\end{array}$ & $\begin{array}{l}60 \\
60\end{array}$ & $\begin{array}{l}2 \\
2\end{array}$ & $\begin{array}{l}13.33 \\
13.33\end{array}$ & $\begin{array}{l}13 \\
13\end{array}$ & $\begin{array}{l}86.66 \\
86.66\end{array}$ \\
\hline Prashanth kumar [7] & $\begin{array}{l}\text { M-28 } \\
\text { F-22 }\end{array}$ & 50 & $\begin{array}{l}20 \\
13 \\
\end{array}$ & $\begin{array}{l}71.4 \\
59.09 \\
\end{array}$ & $\begin{array}{l}8 \\
9 \\
\end{array}$ & $\begin{array}{l}28.57 \\
40.90 \\
\end{array}$ & & & & \\
\hline Present study & $\begin{array}{l}\text { M-30 } \\
\text { F-30 }\end{array}$ & 60 & $\begin{array}{l}14 \\
16 \\
\end{array}$ & $\begin{array}{l}46.66 \\
53.33 \\
\end{array}$ & $\begin{array}{l}16 \\
14 \\
\end{array}$ & $\begin{array}{l}53.33 \\
46.66 \\
\end{array}$ & $\begin{array}{l}13 \\
12 \\
\end{array}$ & $\begin{array}{l}43.33 \\
40\end{array}$ & $\begin{array}{l}17 \\
18 \\
\end{array}$ & $\begin{array}{l}56.66 \\
60 \\
\end{array}$ \\
\hline
\end{tabular}

The present study shows that the incidence of isometry to be more in males and anisometry of hyoid bones to be more in females, while in the study conducted by Bhavna kalyan [6] no such difference could be seen. The incidence of isometry was $13 \%$ in both males and females, for anisometry incidence was $86 \%$ in both male and females. Remaining studies [2, 5] the incidence of isometry to be more in females and anisometry to be more in males.
Table 3 compares the incidence of symmetry and isometry in a given population irrespective of sex. As evident from the table 03 the present study shows that the number of symmetrical bone was equal to the number of asymmetrical bones. Where as in the study conducted by Bhavna kalyan [6] the number of asymmetrical bones were more as compared to symmetrical bones. In other studies $[2,4,5,7]$ the number of symmetrical bones were more as compared to asymmetrical bones.

Table-3: Comparison of present study with other studies

\begin{tabular}{|l|l|l|l|l|l|l|l|l|l|}
\hline \multirow{2}{*}{ Authors } & \multirow{2}{*}{ Total } & \multicolumn{2}{|c|}{ symmetric } & \multicolumn{2}{|c|}{ asymmetric } & \multicolumn{2}{|l|}{ isometry } & \multicolumn{2}{|c|}{ anisometry } \\
\cline { 3 - 11 } & & No & \% & No & \% & No & \% & No & \% \\
\hline Papadopoulos [2] & 76 & 40 & 52.63 & 36 & 47.36 & 38 & 50 & 38 & 50 \\
\hline Leksan et al. [4] & 70 & 60 & 85.71 & 10 & 14.2 & & & & \\
\hline Jadhav Aswini S [5] & 91 & 62 & 68.13 & 29 & 31.86 & 68 & 74.17 & 23 & 25.27 \\
\hline Bhavna kalyan [1] & 30 & 12 & 40 & 18 & 60 & 4 & 13.33 & 26 & 86.66 \\
\hline Prashanth kumar [7] & 50 & 33 & 66 & 17 & 34 & \multicolumn{7}{|c|}{} \\
\hline Present study & 60 & 30 & 50 & 30 & 50 & 25 & 41.66 & 35 & 58.33 \\
\hline
\end{tabular}

With regard to isometry, in the present study the number of anisometric bones were more compared to isometric bones. This observation is comparable with study done by Bhavna kalyan [6]. Where as in the study conducted by Papadopoulos reported that the number of isometric bones was equal to anisometric bones. Jadhav Ashwini $S$ [5] found that the number of isometric bones was more compared to anisometric bones. This difference may be due to the racial factors.

\section{CONCLUSION}

The incidence of anisometry is more as compared with isometry in the hyoid bones, where as the incidence of asymmetrical bones was equal to the incidence of symmetrical bones. Symmetry/asymmetry and isometry/anisometry of hyoid bones do not depict any sex difference which may be due to racial factors.

\section{REFERENCES}

1. Urbanová, P., Hejna, P., Zátopková, L., \& Šafr, M. (2013). What is the appropriate approach in sex determination of hyoid bones?. Journal of forensic and legal medicine, 20(8), 996-1003.

2. Papadopoulos, N., Lykaki-Anastopoulou, G., \& Alvanidou, E. L. (1989). The shape and size of the human hyoid bone and a proposal for an alternative classification. Journal of anatomy, 163, 249.

3. Standring, S. (2008). In chapter: Neck, Bones, Joints and Cartilages In: Grays's Anatomy. The 
Anatomical basis of clinical practice. $40^{\text {th }} \mathrm{Ed}$. London: Elsevier Churchill Livingstone, 443.

4. Lekšan, I., Marcikić, M., Nikolić, V., Radić, R., \& Selthofer, R. (2005). Morphological classification and sexual dimorphism of hyoid bone: new approach. Collegium antropologicum, 29(1), 237242.

5. Jadhav Ashwini, S., \& Kulkarni, P. R. (2012). Variations in the Shape of Human Hyoid Bone in Western Maharashtra. Indian Journal of Anatomy, 1(1).
6. Kalyan, B., Singla, R. K., \& Sharma, R. K. (2018). Symmetry and isometry of human adult hyoid bone: A cadaveric study in North Indian population. CHRISMED Journal of Health and Research, 5(2), 96.

7. Kumar, P., Tambe, S. V., Rahule, A. S., \& Kamdi, N. Y. (2014). Morphology of Hyoid Bone with its Forensic Implication. Journal of Evolution of Medical and Dental Science, 2(2), 4-8. 